\title{
Minimizing Drying Shrinkage and Enhancing Impermeability of Foam Concrete Modified with Epoxy Resin
}

\author{
Jianqing Gong $\mathbb{D}^{1,2}$ and $\mathrm{Ke} \mathrm{Li} \mathbb{D}^{1,2}$ \\ ${ }^{1}$ Key Laboratory for Green \& Advanced Civil Engineering Materials and Application Technology of Hunan Province, \\ Changsha 410082, China \\ ${ }^{2}$ College of Civil Engineering, Hunan University, Changsha, Hunan 410082, China
}

Correspondence should be addressed to Jianqing Gong; gongjianqing@hnu.edu.cn

Received 21 May 2020; Revised 20 July 2020; Accepted 25 July 2020; Published 20 August 2020

Academic Editor: Qiang Tang

Copyright (c) 2020 Jianqing Gong and Ke Li. This is an open access article distributed under the Creative Commons Attribution License, which permits unrestricted use, distribution, and reproduction in any medium, provided the original work is properly cited.

\begin{abstract}
Relatively high drying shrinkage and permeability were two of the major challenges associated with foam concrete (FC), primarily due to its high porosity nature. This study was aimed at reducing the drying shrinkage and improving the impermeability of FC by blending and modifying it with epoxy resin (EP). Extensive laboratory testing yielded an optimum content of $4.0 \%$ EP, corresponding to a minimum drying shrinkage rate of $1.47 \mathrm{~mm} / \mathrm{m}$, which was $48 \%$ lower than that of the unmodified FC. At this optimum dosage of $4.0 \% \mathrm{EP}$, the permeability pressure was at a maximum level of $1.4 \mathrm{MPa}$, whereas the permeability coefficient was at its lowest value of $0.75 \times 10^{-9} \mathrm{~mm} / \mathrm{h}$. Internal pore structure and EP distribution were characterized using the scanning electron microscopy and indicated that a microgrid structure of the FC was formed internally, featuring an increase in the number of pores, a reduction in the average pore size, and a uniform pore size distribution. Similarly, surface energy measurements using the tensiometry method yielded maximum surface energy values at $4.0 \%$ EP content, which could be used to explain the reduced drying shrinkage and the enhanced impermeability characteristics of the modified FC.
\end{abstract}

\section{Introduction}

Foam concrete (FC) is a composite of cement slurry containing aggregates and foam. Foam concrete is characterized with favorable fluidity, fire, and heat resistance and is lightweight, environmentally-friendly, and cost effective [1]. Foam concrete has been traditionally used in separating panels, filling, and cushioning materials. However, recent advances in FC technology have seen their use in applications where a high-performance material is required [2-10], e.g., highways, military, civil engineering, and aviation [11-15]. Foam concrete has been successfully used in the backfilling of underground projects such as building compensation foundation treatment, and it can be used to widen the roadbed to effectively reduce differential settlement $[16,17]$. Unfortunately, FC is not only affected by loading [7], but also the environment. In particular, shrinkage and water penetration into its internal porous structure [18] tend to degrade its durability and longevity [19-24]. Both the shrinkage and permeability of FC depend on the pore structure, size, surface area, and connectivity [2-5].

Microstructure defects such as the permeable pores in the lightweight FC will significantly affect its shrinkage and permeability properties. The migration of water inside the concrete is the major factor affecting the shrinkage and permeability of FC. Prim and Wittmann investigated water adsorption into aerated concrete [4] and concluded that the propensity to adsorb water was related to the pore structure, where the capillary coefficients decreased as the size of the artificially blown holes increased. Research by Madjoudj et al. showed that porous and lightweight FC had a smaller water absorption capacity than high-density concrete [3]. Nambiar and Ramamurthy used FC specimens containing different contents of fly ash, sand, and foam volumes to show that the water absorption capacity was lower than its 
corresponding matrix without foam and that the adsorption capacity decreased as the foam content increased [2]. Nambiar and Ramamurthy also discovered that pores containing trapped air were not able to absorb water, as the air could not be displaced. Therefore, it is necessary to investigate the impact of pore structure and microstructure of FC on its drying shrinkage and water permeability characteristics in order to improve its performance, durability, and longevity [5].

The mechanism of moisture movement within the FC is more complicated due to the large range of pore sizes, from large single pores to microcracks and pores in the pore-walls, formed during blowing $[2,5,25]$. To enhance the drying shrinkage resistance and impermeability, blending and reinforcing the FC with polymer additives using cost-effective simple methods improved mechanical performance, water retention, and impermeability and also increased the resistance to carbonization and chloride ion penetration [9]. Al-Nasra and Daoud found that the addition of a superabsorbent polymer improved the concrete's strength, plasticity, stability, and water impermeability [10]. Epoxy resin is a chemically stable and low-absorbent polymer that undergoes low shrinkage and has good abrasion resistance [20, 26]. Therefore, the blending of EP into FC that is envisioned would dramatically reduce the FC's drying shrinkage and enhance its (FC) impermeability.

Griffith et al. developed the theory of crack propagation through brittle materials, which considered classical mechanics and thermodynamic concepts such as surface energy (SE) and energy conservation theories [19-21, 27-29]. Hori concluded that, for mortar immersed in a liquid, its surface tension increased [19]. Since then, the relationship between the change in SE and the performance of FC has been well studied from the perspective of SE. As documented by many research scholars, the ability for water to be absorbed by concrete can be deduced from the SE concepts [20-23]. The relationship between concrete and water has a great influence on the shrinkage and permeability properties of FC. From the literature reviewed, however, there is limited documentation on the relationship between moisture content and drying shrinkage and water permeability of concrete from the perspective of SE.

The existing research on polymer modified FC from across the globe mostly focused on the changes to the surface characteristics such as physical properties and thermal performance $[8-10,26,30,31]$. Thus, it is necessary to further investigate the effects of polymers on the structure and changes in the SE of the pores inside the FC. In this study, the effects of EP on the shrinkage and impermeability properties of $\mathrm{FC}$ were evaluated by adding different dosages of the waterborne EP into FC. Scanning Electron Microscopy (SEM) was used to examine the pore size distribution and pore diameter. Concurrently, the effects of EP blend with FC on the pore structure, shape, connectivity, and SE were also studied. The study, as presented in this paper, ultimately provided a theoretical analysis and a basis for the probable use of EP in improving the performance, durability, and longevity of FC.

\section{Materials and Mix Proportions}

2.1. Materials. Grade 42.5 ordinary Portland cement, which met the requirements of China's GB175-2007 Standard [32], was blended with Grade 42.5 rapid-hardening sulfoaluminate cement to prepare FC. The physical and chemical properties of the mixed cement were in accordance with the BSEN 196-1-2005 Standard [33]. The foam in the concrete was produced following the physical foaming method [34]. The foaming agent, Type GS-1, was a planted protein-based anionic surfactant. The specific parameters of the air compressor and foaming agent are provided in Tables 1 and 2 , respectively.

The epoxy resin used in this study was in an emulsion form, with a solids content of $50 \%$ and a specific gravity varying between 1.01 and 1.08. The compatibility between the EP and foam met the requirements specified by the BS EN 9342 Standard [35]. A specific curing agent was used at a mixing ratio of $3: 1$ to cure the resin. The slag powder had a density of $2920 \mathrm{~kg} / \mathrm{m}^{3}$, a specific surface area of $422 \mathrm{~m}^{2} / \mathrm{kg}$, and an average particle size of $0.15 \mathrm{~mm}$. The silica fume had a density of $220 \mathrm{~kg} / \mathrm{m}^{3}$, a specific surface area of $1.85 \times 10^{4} \mathrm{~m}^{2} / \mathrm{kg}$, and an average particle size of $89 \mathrm{~nm}$. Class I fly ash used was in accordance with the ASTM C618 Standard [36]. A polycarboxylate water-reducing agent, with a water-reducing ability of over $25 \%$, was used in this study.

2.2. Mix Proportions. The water-to-cement ratio was fixed at 0.19 [34]. Ordinary Portland cement was blended with sulfoaluminate cement at a weight ratio of $9: 1[1,37]$. A series of FC specimens with the same density of $1500 \mathrm{~kg} / \mathrm{m}^{3}$ [34] were prepared by adding graduated dosages $(0.0 \%$, $2.5 \%, 3.0 \%, 3.5 \%, 4.0 \%$, and $4.5 \%)$ of EP into the mixed cement. Details are provided in Table 3.

2.3. Specimen Preparation. Nine specimens, comprising a group of three specimens for the shrinkage test and a group of six specimens for the permeability test, were prepared for each condition. Shrinkage specimens were prepared with the prismatic dimensions of $40 \mathrm{~mm} \times 40 \mathrm{~mm} \times 160 \mathrm{~mm}$. Probes were preburied at the two ends of each specimen. Permeability specimens were prepared with a circular truncated cone shape with a top diameter of $70 \mathrm{~mm}$, a bottom diameter of $80 \mathrm{~mm}$, and a height of $30 \mathrm{~mm}$.

Each solid component, as listed in Table 3, was mixed in a mortar mixer at a low stirring rate for $1 \mathrm{~min}$. An aqueous solution of water-reducing agent was prepared by dissolving the water-reducing agent in tap water. The solution was then added into an agitator kettle and mixed for $1 \mathrm{~min}$. Materials stuck on the bottom and inner walls of the mixer were scraped off and mixed with the whole mix. Foaming agent, diluted with water in a ratio of $1: 40$, was poured into the foaming machine for foaming. Liquid foam, with a density of $50 \mathrm{~kg} / \mathrm{m}^{3}$, was produced in the foaming machine. The foam was mixed with the solid components in the mortar mixer and stirred for about $1 \mathrm{~min}$ until the foam was uniformly dispersed in the cement paste. The epoxy resin and curing agent were then added into the mixer and stirred gently for 
TABLE 1: Technical parameters of the air compressor.

\begin{tabular}{lccccc}
\hline Type & Volume $(\mathrm{L})$ & Volume flow rate $\left(\mathrm{m}^{3} / \mathrm{min}\right)$ & Voltage to frequency $(\mathrm{V}-\mathrm{Hz})$ & Exhaust pressure $(\mathrm{MPa})$ & $\mathrm{Rotating}$ rate $(\mathrm{r} / \mathrm{min})$ \\
\hline BAD-50 & 50 & 3.45 & 64.65 & 2.36 & 2.44
\end{tabular}

TABle 2: Performance parameters of the foaming agent.

\begin{tabular}{cccccc}
\hline Type & Density $\left(\mathrm{g} / \mathrm{cm}^{3}\right)$ & Subsidence distance $(\mathrm{mm} / \mathrm{h})$ & Bleeding rate $(\mathrm{g} / \mathrm{h})$ & Dilution factor & Foaming factor \\
\hline GS-1 & 1.00 & 5 & 20 & 40 & 20 \\
\hline
\end{tabular}

TABle 3: Composition of FC specimens $\left(\mathrm{kg} / \mathrm{m}^{3}\right)$.

\begin{tabular}{lcccccccccc}
\hline Group no. & P.O. 42.5 & R.SAC42.5 & Silica fume & Fly ash & Slag & Water & Foam & Water reducing agent & EP & Epoxy curing agent \\
\hline b0 & 2363.0 & 262.6 & 787.7 & 1050.2 & 262.5 & 898.0 & 66.8 & 70.9 & 0 & 0 \\
b1 & 2363.0 & 262.6 & 787.7 & 1050.2 & 262.5 & 898.0 & 66.8 & 70.9 & 65.6 & 21.9 \\
b2 & 2363.0 & 262.6 & 787.7 & 1050.2 & 262.5 & 898.0 & 66.8 & 70.9 & 78.8 & 26.3 \\
b3 & 2363.0 & 262.6 & 787.7 & 1050.2 & 262.5 & 898.0 & 66.8 & 70.9 & 91.9 & 30.6 \\
b4 & 2363.0 & 262.6 & 787.7 & 1050.2 & 262.5 & 898.0 & 66.8 & 70.9 & 105.0 & 35.0 \\
b5 & 2363.0 & 262.6 & 787.7 & 1050.2 & 262.5 & 898.0 & 66.8 & 70.9 & 118.2 & 39.4
\end{tabular}

no more than 1 min until they were evenly dispersed within the cement slurry. The mixed paste containing EP and foam was then poured into the corresponding molds and set under ambient conditions for 24 hours for specimen molding and fabrication.

\section{Laboratory Test Methods}

3.1. Drying Shrinkage. The drying shrinkage of FC specimens was measured with an SP-175 length comparator following the procedures specified by the ASTM C157-2008 Standard [30] and China's GB/T 11969-2008 Standard [38], which included the moisture content determination.

3.2. Impermeability. There are currently no standard testing procedures for impermeability measurements in FC. A modified water penetration depth method was used to calculate relative permeability coefficients using Darcy's law, which was then used to characterize the overall permeability of the FC [7, 39, 40]. Three replicate specimens per EP dosage were used for determining the relative permeability coefficients.

3.2.1. Impermeability Pressure Value. Specimens were set for 24 hours, removed from the mold, and then kept in a constant temperature $\left(20 \pm 2^{\circ} \mathrm{C}\right)$ and humidity $(60 \pm 5 \%)$ oven for 28 days. Thereafter, specimens were entirely coated with a complete layer of sealant. The mass of each sealed specimen was then measured and designated as $m_{0}$. Their impermeability was tested with a SS-1.5 permeameter [40]. Initially, a water pressure of $0.2 \mathrm{MPa}$ was applied, maintained for 2 hours, and then increased to $0.3 \mathrm{MPa}$ if no water was exuded. After that, the water pressure was increased by $0.1 \mathrm{MPa}$ hourly until half of the specimens in each group started to exude water, at which point the test was terminated. The final water pressure was recorded and designated as $H$. The impermeability pressure, $P$, was calculated using

$$
P=H-0.1
$$

3.2.2. Determination of the Permeability Coefficient. If specimens have good permeability and did not exude water after the water pressure was increased to $1.5 \mathrm{MPa}$, then the water pressure was maintained constant for 6 hours, after which the mass of specimens was recorded and designated as $m$. Specimens were subsequently mounted in a press. Both the upper and lower ends of specimens were separated from the holders of the press by attaching a steel rod with a diameter of $6 \mathrm{~mm}$ to each end of the press. The two steel rods were then sandwiched between the ends of the specimen, and the holders of the press were placed on the centerline of each end of the specimen. The press was then powered on, and the specimen was split into two pieces along its longitudinal section. The water marks on the fracture surface were marked out with a waterproof marker pen. A trapezoidal transparent plastic plate was placed on the fractured surface of the specimen. A steel ruler was then used to measure the distance from the bottom of the specimen to the intersection of the water marks and the 8 vertical lines (Figure 1). The length was measured and recorded to an accuracy of $1 \mathrm{~mm}$.

For each specimen, the arithmetic mean value $(\bar{h})$ of eight water exudation heights $\left(h_{i}\right)$ was taken as its water penetration depth $(h)$ in $\mathrm{mm}$. The permeability coefficient $K_{p}$ was calculated using the following equation [40]:

$$
K_{p}=\frac{h^{2} v}{2 t \Delta P}
$$

where $K_{p}$ is the permeability coefficient, $h$ is the average water penetration depth, $v$ is the porosity of the test specimen, $t$ is the length of time, during which the test specimen was pressurized, and $\Delta P$ is the pressure difference (which has been converted to the height of the water column). The 


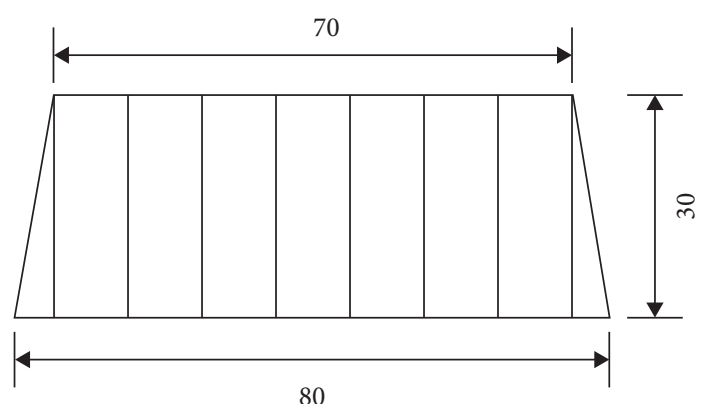

FIGURE 1: Schematic diagram of the trapezoidal transparent plastic plate $(\mathrm{mm})$.

porosity of the test specimen, $v$, was obtained through approximation using [7]

$$
v=\frac{V_{w}}{A h}
$$

where $V_{w}$ is the volume of water, which infiltrated into the specimen, and $A h$ is the volume of the specimen. Finally, the volume of water, which infiltrated into the specimen, was calculated using equations (4) and (5), respectively:

$$
\begin{gathered}
V_{w}=\frac{\Delta m}{\rho_{\text {water }}}, \\
\Delta m=m-m_{0},
\end{gathered}
$$

where $m_{0}$ and $m$ are the masses of specimens before the test and after the test, respectively. Note that, for both the impermeability pressure and permeability coefficient determination, three replicate specimens were used per test condition per EP dosage.

3.3. Scanning Electron Microscopy. SEM micrographs were captured using a Gemini 300 scanning electron microscope (ZEISS, Germany). The SEM test was conducted to characterize the morphology, microstructure, and pore size distribution of the FC. Specimens were prepared for SEM analysis by soaking in ethanol for 7 days to stop hydration. Specimens were then dried in a vacuum drying oven at $60 \pm 5^{\circ} \mathrm{C}$ until their weight reached constant values. A small $1 \mathrm{~cm}^{3}$ specimen was extracted from each specimen and sputter-coated with gold before analysis. Three replicate specimens were evaluated per EP dosage.

3.4. Surface Energy. The contact angle of $(\theta)$ a water droplet on the specimen was measured with a DataPhysics DCAT21 interfacial tensiometer, from which the SE of the concrete was calculated using equation (6) [41] derived from the adhesion work formulation and Young's model:

$$
W_{\alpha}=\gamma_{L V}(1+\cos \theta)
$$

where $W_{\alpha}$ is the adhesion work, and $\gamma_{L V}$ is free energy at the interface between liquid and gas.

In this study, the SE test was conducted to quantify the adhesion and bonding characteristics among the various FC constituent elements. The lower the contact angle, the higher the SE and the stronger the adhesion/bonding-and vice versa [42]. For each EP dosage, three replicate specimens were evaluated.

\section{Test Results and Discussions}

4.1. Drying Shrinkage. Due to a large number of pores in FC [43], high moisture content, rapid moisture dissipation, and changes to the internal structure led to a relatively large degree of shrinkage. Mixed cement, consisting of $60 \%$ ordinary Portland and $40 \%$ rapid-hardening sulfoaluminate cement, was used in this study. A series of modified FC were prepared by adding graduated dosages $(0.0 \%, 2.5 \%, 3.0 \%$, $3.5 \%, 4.0 \%$, and $4.5 \%)$ of EP into the FC before curing. The drying shrinkage values of the FC specimens were measured as previously discussed in Section 3.

4.1.1. Effects of Moisture Content on Drying Shrinkage. Experimentally determined moisture contents and shrinkage values of the FC specimens with different EP contents are summarized in Table 4. Shrinkage values first decreased gradually between moisture contents $14 \%$ and $4 \%$ and, then, sharply increased between $4 \%$ and $2.5 \%$ (Figure 2). Water lost during the early high water-content stage (i.e., $14 \%$ and $4 \%$ ) came from the largest pores, which had a minimal effect on shrinkage [44].

Any decline in shrinkage during the early high watercontent stage was attributed to the continuation of the hydration reaction of concrete during this time [7, 34]. It may be that the formation rate of ettringite and C-S-H gel was higher than the rate of water dissipation. However, an increase in polymer content allowed more water to be stored in a greater fraction of continuous polymer membrane, which minimized the impact of water loss on shrinkage at an increasingly high polymer content.

From Table 4, when the EP content increased from $2.5 \%$ to $4.5 \%$, the maximum moisture contents varied from $10.68 \%$ to $12.02 \%$, and their variation ranges were approximately the same. The effect of decreasing moisture content on the shrinkage value was smallest for specimen b4, where the EP content was $4 \%$. As the moisture content decreased from $14.31 \%$ to $2.54 \%$, the shrinkage value changed by $1.48 \mathrm{~mm} / \mathrm{m}$. This represented a ratio of changes in shrinkage value versus changes in moisture content of 0.12 . The ratios calculated for specimens b0, b1, b2, b3, and b5 were $0.17,0.17,0.16,0.15$, and 0.13 , respectively. The addition of EP into the concrete was, therefore, shown to decrease the sensitivity of the shrinkage value to the change in moisture content, which was attributed to the changes in the internal structure and SE (adhesion/bonding) characteristics. It was apparent that the bonding effect of EP created a dense mesh structure within the FC as the pores became filled with EP. This was likely to affect water dissipation and support the internal structure. As an admixture, EP also influenced SE and adhesion/bonding characteristics, the impact of which is discussed in the subsequent text. 
TABLE 4: Experimentally determined moisture contents (MC) and shrinkage values (SV).

\begin{tabular}{lcccccccccccc}
\hline & b0 & \multicolumn{3}{c}{ b1 } & \multicolumn{3}{c}{ b2 } & \multicolumn{3}{c}{ b3 } & \multicolumn{3}{c}{ b4 } \\
MC & SV & MC & SV & MC & SV & MC & SV & MC & SV & MC & SV \\
\hline 3.18 & 0.90 & 2.43 & 0.48 & 2.54 & 0.26 & 2.42 & 0.58 & 2.54 & -0.36 & 2.57 \\
3.31 & 0.10 & 2.51 & 0.31 & 2.56 & 0.12 & 2.44 & 0.38 & 2.57 & -0.57 & 2.60 & 0.85 \\
3.44 & -0.43 & 2.65 & 0.25 & 2.74 & -0.05 & 2.61 & -0.01 & 2.75 & -0.89 & 2.78 & 0.56 \\
3.47 & -0.63 & 2.76 & 0.18 & 2.77 & -1.00 & 2.64 & -0.50 & 2.78 & -1.17 & 2.81 & 0.39 \\
3.48 & -0.66 & 2.88 & 0.10 & 2.82 & -1.32 & 2.69 & -0.73 & 2.83 & -1.43 & 2.86 & 0.14 \\
3.49 & -0.66 & 2.91 & 0.05 & 3.10 & -1.44 & 2.76 & -0.93 & 3.12 & -1.65 & 3.17 & -0.19 \\
3.50 & -0.66 & 3.06 & -0.11 & 3.13 & -1.51 & 2.87 & -1.17 & 3.15 & -1.95 & 3.17 & -0.34 \\
3.56 & -1.21 & 3.13 & -0.21 & 3.20 & -1.69 & 2.97 & -1.40 & 3.17 & -2.21 & 3.24 & -0.52 \\
3.57 & -1.27 & 3.15 & -0.67 & 3.27 & -1.69 & 2.99 & -1.55 & 3.21 & -2.36 & 3.31 & -0.56 \\
3.79 & -1.44 & 3.18 & -0.89 & 3.37 & -1.84 & 3.18 & -1.45 & 3.34 & -2.31 & 3.39 & -0.64 \\
4.02 & -1.12 & 3.27 & -1.33 & 3.59 & -1.66 & 3.40 & -1.13 & 3.56 & -1.84 & 3.43 & -0.39 \\
15.20 & 0.00 & 13.11 & 0.00 & 14.15 & 0.00 & 13.37 & 0.00 & 14.31 & 0.00 & 14.11 & 0.00 \\
\hline
\end{tabular}

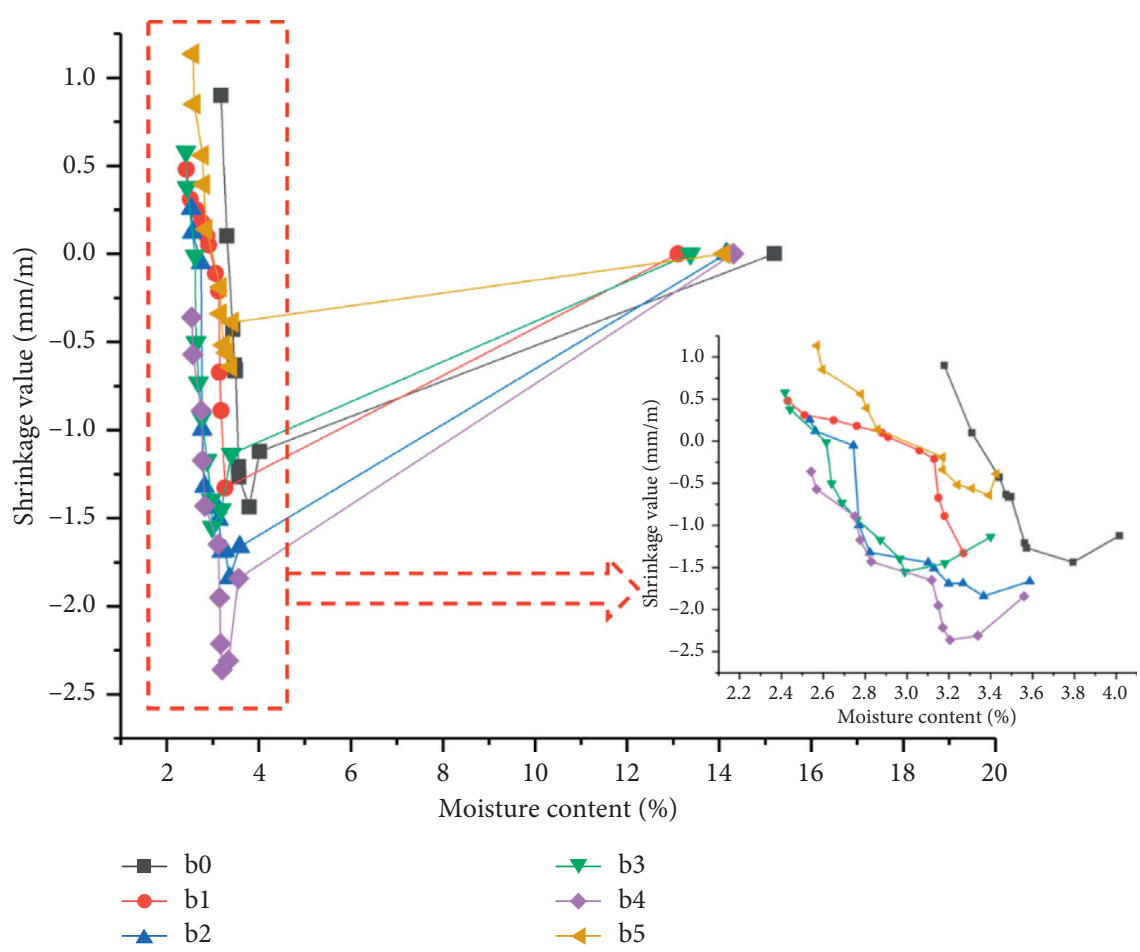

Figure 2: Graphical correlations between shrinkage value and moisture content.

4.1.2. Effects of Age on Drying Shrinkage. The shrinkage values of EP-FC specimens at different curing times are summarized in Table 5. The drying shrinkage of concrete depended on the dissipation of adsorbed water from the surface of the hydrated gel particles. Drying shrinkage of ordinary FC is about $2 \mathrm{~mm} / \mathrm{m} \sim 3.5 \mathrm{~mm} / \mathrm{m}$ [34]. Compared with the shrinkage of ordinary FC, the drying shrinkage values of all test specimens were relatively low as shown in Figure 3.

Figure 3 shows that as the EP content increased, the drying shrinkage values measured after 56 days of curing gradually decreased, with the b4 specimen yielding the smallest drying shrinkage value of $1.47 \mathrm{~mm} / \mathrm{m}$. Due to the pore-filling effect of the internalized EP membrane, the pore walls of the concrete became denser. This enabled the generation and distribution of the hydration products to
TABle 5: Shrinkage values $(\mathrm{mm} / \mathrm{m})$ of the FC specimens with different contents of EP after different curing times.

\begin{tabular}{lcccccc}
\hline Time (days) & b0 & b1 & b2 & b3 & b4 & b5 \\
\hline 0 & 0 & 0 & 0 & 0 & 0 & 0 \\
3 & 0.45 & 1.08 & 0.81 & 0.60 & 0.46 & 1.25 \\
7 & 1.45 & 1.80 & 1.72 & 1.30 & 0.75 & 1.71 \\
14 & 1.75 & 1.51 & 1.38 & 1.24 & 0.60 & 1.65 \\
21 & 1.95 & 2.12 & 1.83 & 1.44 & 1.38 & 2.31 \\
28 & 2.71 & 2.14 & 1.93 & 1.49 & 1.40 & 2.36 \\
56 & 2.81 & 2.27 & 2.17 & 1.65 & 1.47 & 2.49 \\
\hline
\end{tabular}

become more homogeneous throughout the specimen matrix and, thereby, enhanced the resistance to shrinkage.

Generally, the walls of the pores within FC feature numerous, tiny pores and cracks as well as gaps between the 


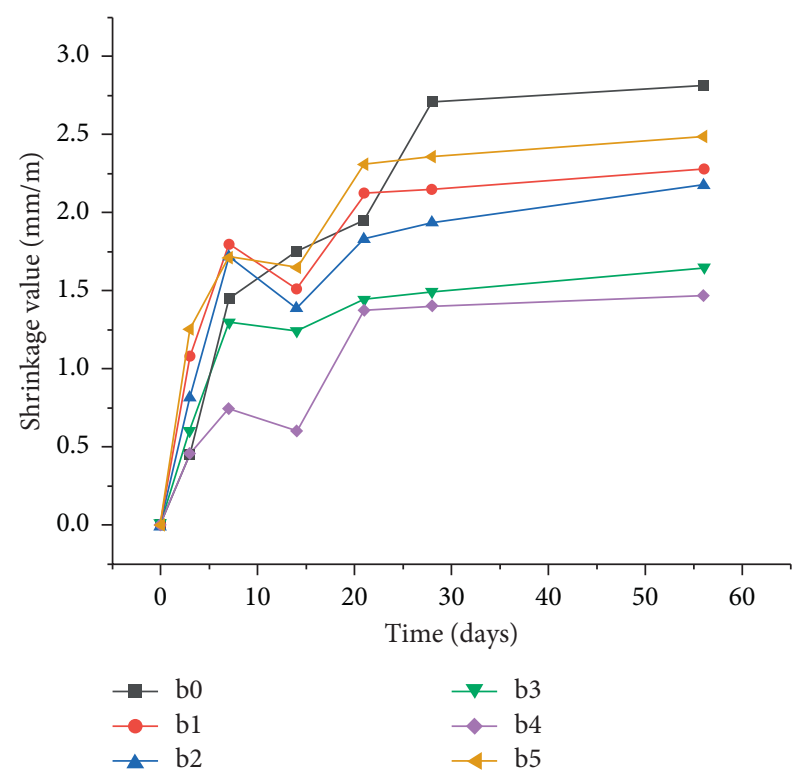

Figure 3: Effect of curing age on the shrinkage values of the FC specimens with different contents of EP.

pores themselves. EP served to fill the pore walls [26, 31], improve the pore structure, reduce the occurrence of weak pores, and densify the pore wall structure. At the same time, the film structure formed by the curing reaction can fill the internal pore and microcracks. Ameliorate the structure of the pore wall, thus reducing water migration and improving resistance to drying shrinkage, which was elaborated in microstructural analysis section. The toughness and resistance to shrinkage were consequently improved and enhanced. Additionally, the EP membrane formed on the surface of the hydration products also helped reduce water loss and promoted the hydration reaction. The introduction of the microfiber mesh structure caused by filling of the micropores by EP strengthened the internal structure, increased the force bearing point, and weakened the capillary action, with an overall improvement in the resistance of FC to drying shrinkage.

4.1.3. SEM Morphological Results. The morphology and microstructure of the end-products in the EP-enriched FC specimens were characterized using the SEM test. As shown in Figure 4, the unmodified FC in specimen b0 comprised a huge amount of scattered distributed needle-shaped ettringite and plate-shaped calcium hydroxide, which overlapped to form numerous gaps and pores throughout the concrete. The number of pores and gaps decreased with increasing EP content (Figures 4-7). The surface of the hydration products was uniformly covered by the EP membrane, which structurally connected them, thus enhancing both the resistance to shrinkage and the bulk stability (Figure 6). Additionally, the gaps and cracks formed by overlapping the hydration products became filled (see Figure 8).

When the EP content was increased to $4.0 \%$, the epoxy resin membrane provided a microfibrous mesh throughout the concrete matrix, which improved the resistance to shrinkage by supporting the structure of the pore walls and the hydrated calcium silicate gel phase (Figure 6). However, when the EP content was increased further to $4.5 \%$, the strong agglutinating force of the EP disrupted the uniform distribution of the hydration products. Consequently, a great number of unhydrated particles became encapsulated and shielded in the EP at an early stage, thus preventing their hydration as visually evident in Figure 9. This infers that the detrimental effects of high EP contents above the optimum dosage overshadow the potential benefits of EP in FC.

The overall foam structure was then examined in detail. In the FC that did not contain EP, the pores were generally large in size with a wide distribution $(\approx 100-200 \mu \mathrm{m})$ as visually seen in Figure 10(a). When the EP content was increased to $4.0 \%$, the average pore size decreased, while the relative number of small pores increased compared to the large pores. Although the pore wall continued to be densified and smoother as the EP content was increased further to $4.5 \%$, the pores became interconnected, which counteracted the cured EP's resistance to drying shrinkage and also increased its permeability; see Figure 11. This was attributed to the high viscosity of the cement paste with high EP contents that prevented homogeneity during mixing. Additionally, excessive EP contents weakened the adhesion and bonding between the chemical admixture and the foam, leading to the foam breakage and separation (Figure 11).

\subsection{Impermeability Characteristics}

4.2.1. Effects of EP Content on Permeability Pressure, Permeability Height, and Permeability Coefficient. The effects of different EP contents on the water exudation pressure of the FC are summarized in Table 6 . The water exudation pressure generally increased as the EP content increased, with the exudation pressures for test specimens $\mathrm{b} 0, \mathrm{~b} 1, \mathrm{~b} 2, \mathrm{~b} 3, \mathrm{~b} 4$, and b5 being $0.3 \mathrm{MPa}, 1.0 \mathrm{MPa}, 1.3 \mathrm{MPa}, 1.5 \mathrm{MPa}, 1.5 \mathrm{MPa}$, and $1.5 \mathrm{MPa}$, respectively. Using equation (1), the final water pressure for each specimen group was then used to calculate the impermeability pressures, $P$, which are plotted in Figure 12. Fewer than three specimens from b3 b4 or b5 exuded water at the highest water pressure. Therefore, the permeability coefficients of specimens b3, b4, and b5 were calculated using Equations (2)-(5). The results are summarized in Table 7.

As shown in Figure 12, the water exudation pressure of FC containing zero EP was the lowest at $0.2 \mathrm{MPa}$. Upon addition of $2.5 \% \mathrm{EP}$, the water exudation pressure increased by almost $350 \%$ to $0.9 \mathrm{MPa}$, while at $3.0 \% \mathrm{EP}$ content, the water exudation pressure increased by further $600 \%$ to 1.4 MPa. The depth of penetration measurements and the calculated permeability coefficients were used to quantify the permeability of specimens at the maximum water exudation pressure.

Specimens b0, b1, and b2 underwent complete water penetration as their depths of penetration of $30 \mathrm{~mm}$ (Table 7). The depth of penetration dramatically decreased as the EP content increased further (Figure 13), with the 

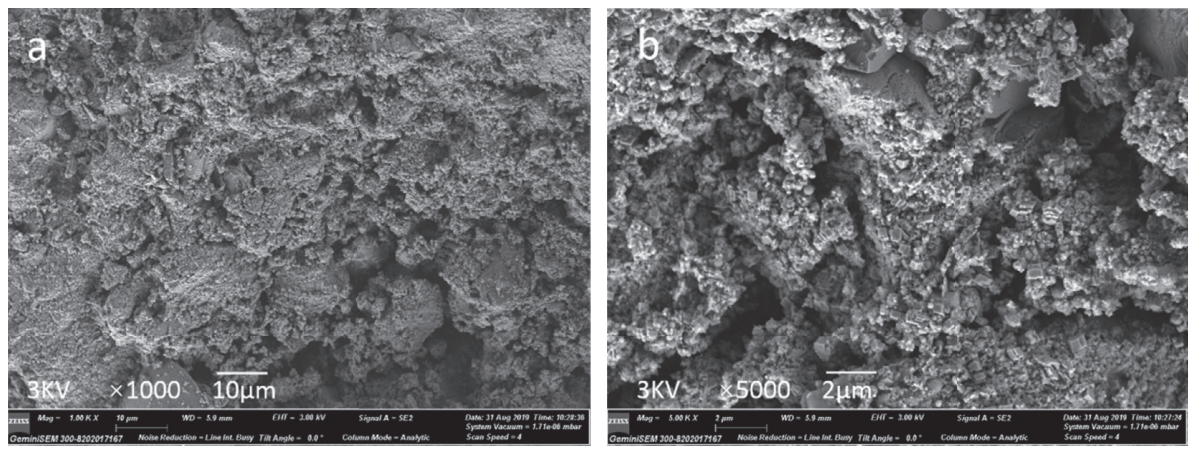

FIGURE 4: SEM micrographs showing the morphology of specimen b0 at 1000x (a) and 5000x (b) magnification.
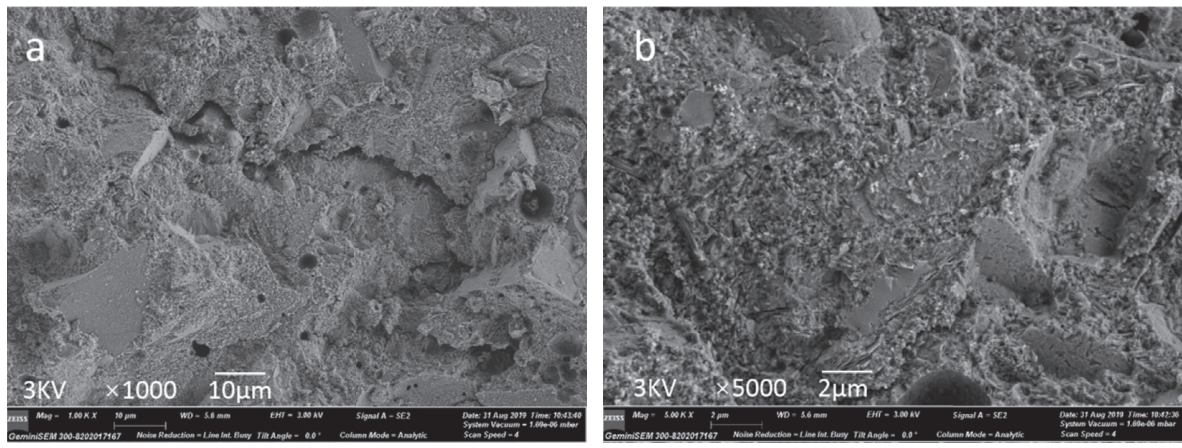

FIGURE 5: SEM micrographs showing the morphology specimen b3 at 1000x (a) and 5000x (b) magnification.
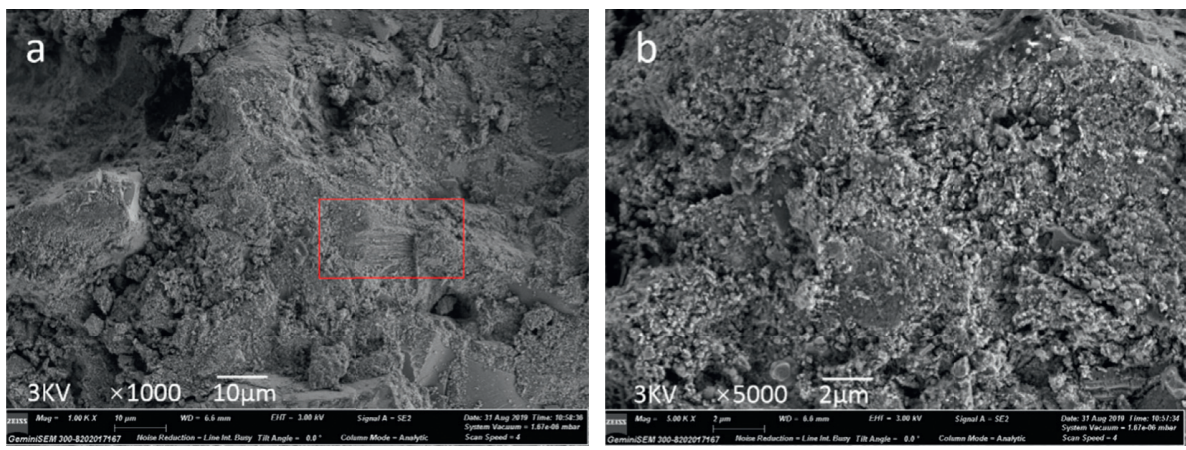

FIGURE 6: SEM micrographs showing the morphology specimen b4 at 1000x (a) and 5000x (b) magnification.
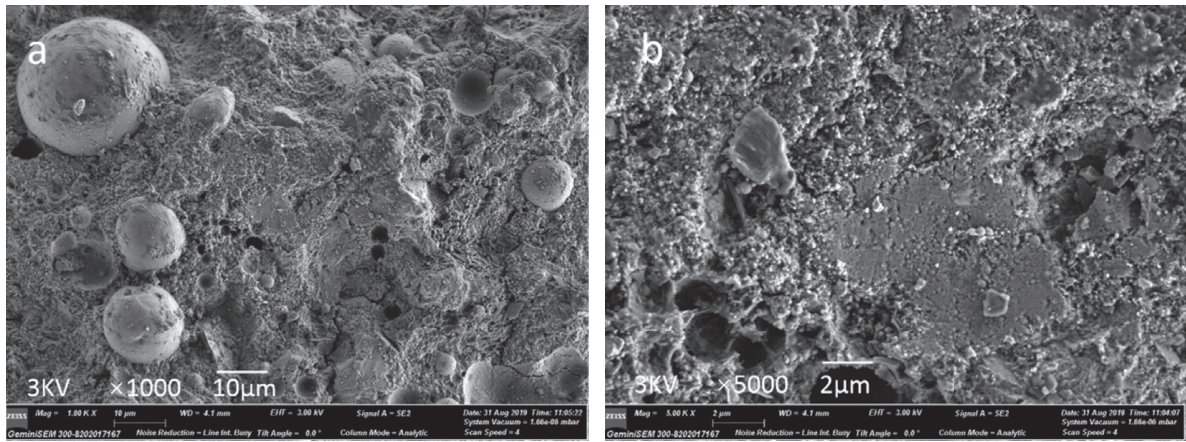

FIGURE 7: SEM micrographs showing the morphology specimen b5 at 1000x (a) and 5000x (b) magnification. 


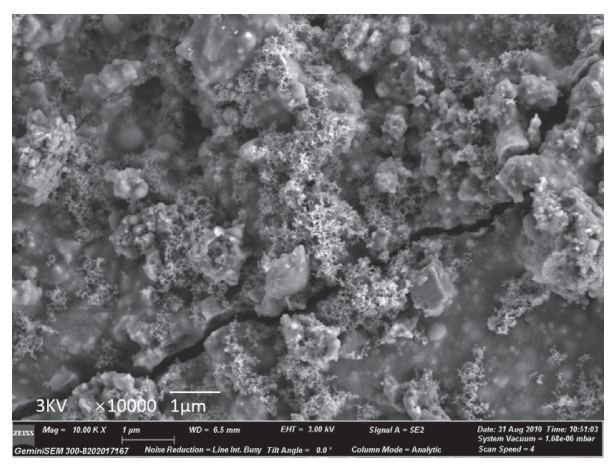

FIGURE 8: SEM micrograph showing the morphology specimen b4 at 10000x magnification.

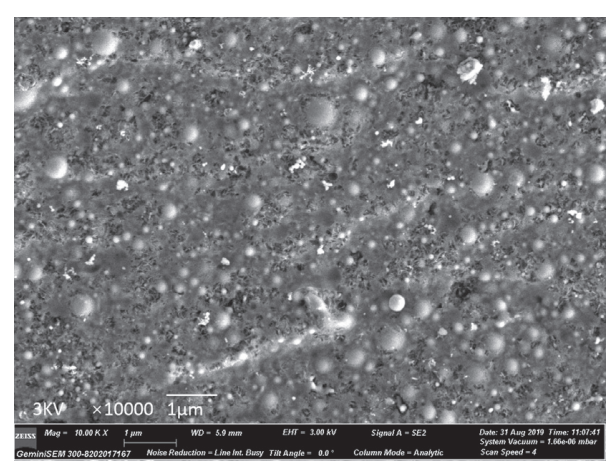

FIGURE 9: SEM micrograph showing the encapsulation of unhydrated particles within the EP membrane in specimen b5 at 10000x magnification.

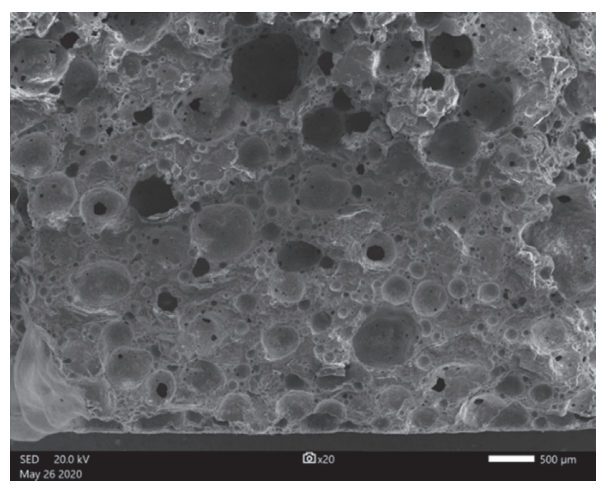

(a)

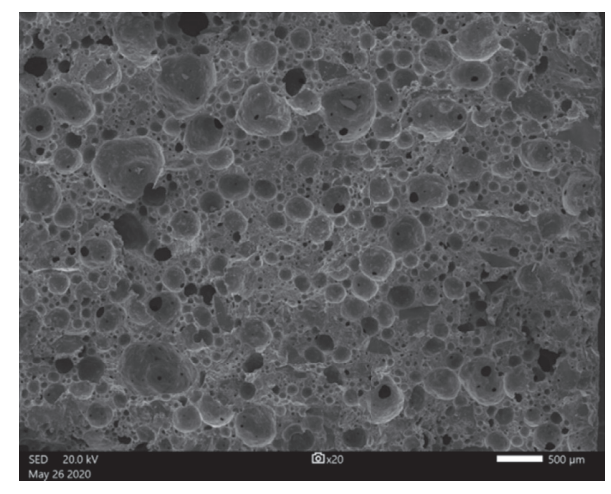

(b)

Figure 10: SEM micrographs of the foam structure \% of specimens (a) b0 (0\% EP) and (b) b4 (4.0\% EP).

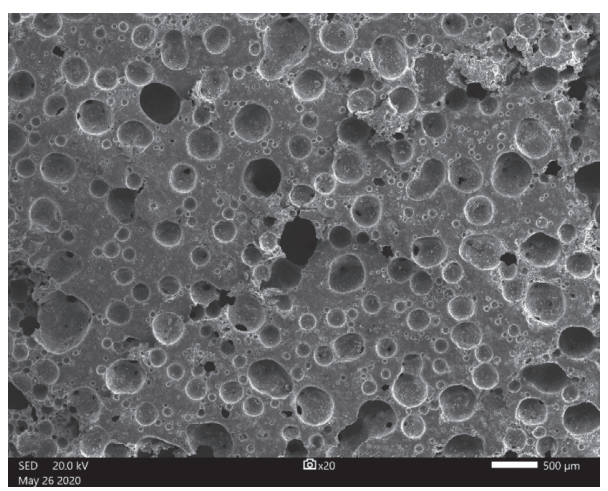

Figure 11: SEM micrograph of the foam structure of specimen b5 (4.5\% EP). 
TABLE 6: Effects of different contents of EP on the water exudation pressure of FC.

\begin{tabular}{|c|c|c|c|c|c|c|c|}
\hline \multirow{2}{*}{ Specimen } & \multicolumn{7}{|c|}{ Water pressure at the end of the experiment, $H(\mathrm{MPa})$} \\
\hline & $A$ & $B$ & $C$ & $D$ & $E$ & $F$ & $P$ \\
\hline $\mathrm{b} 0$ & - & 0.3 & - & 0.2 & 0.3 & - & 0.2 \\
\hline b1 & 0.8 & - & 1 & 1 & - & - & 0.9 \\
\hline b2 & 1.3 & 1.2 & - & - & - & 1.3 & 1.2 \\
\hline b3 & 1.5 & 1.5 & 1.5 & 1.5 & 1.5 & 1.5 & 1.4 \\
\hline $\mathrm{b} 4$ & 1.5 & 1.5 & 1.5 & 1.5 & 1.5 & 1.5 & 1.4 \\
\hline b5 & 1.5 & 1.5 & 1.5 & 1.5 & 1.5 & 1.5 & 1.4 \\
\hline
\end{tabular}

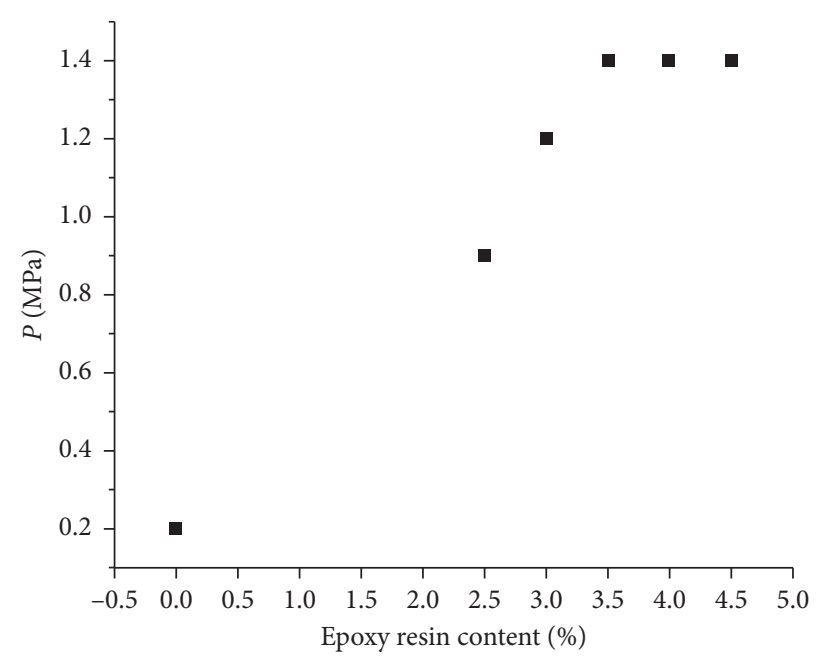

Figure 12: Impermeability pressures, $P$ of FC specimens containing different amounts of EP.

Table 7: Permeability coefficients of specimens b3, b4, and b5.

\begin{tabular}{lccccccc}
\hline $\begin{array}{l}\text { Test } \\
\text { specimen no. }\end{array}$ & $\begin{array}{c}\text { Average depth of } \\
\text { penetration }(\mathrm{mm})\end{array}$ & $\begin{array}{c}\text { Pressurization } \\
\text { time }(\mathrm{t})\end{array}$ & $\begin{array}{c}\triangle P \\
(\mathrm{MPa})\end{array}$ & $\begin{array}{c}\triangle P(\text { height of water } \\
\text { column, mm })\end{array}$ & $\Delta m(\mathrm{~kg})$ & $A h\left(\mathrm{~m}^{3}\right)$ & $K_{P}\left(\times 10^{-9} \mathrm{~mm} / \mathrm{h}\right)$ \\
\hline b3 & 3.33 & 15 & 1.5 & 153000 & 0.0002 & 0.000133 & 3.65 \\
b4 & 2.13 & 15 & 1.5 & 153000 & 0.0001 & 0.000133 & 0.75 \\
b5 & 8.53 & 15 & 1.5 & 153000 & 0.0004 & 0.000133 & 47.81 \\
\hline
\end{tabular}

calculated permeability coefficients, $K_{P}$, of FC specimens containing $3.5 \%, 4.0 \%$, and $4.5 \%$ EP being $3.65,0.75$, and 47.81, respectively (Figure 14). The smallest water penetration depth and permeability coefficient, and, therefore, the highest impermeability, were recorded for the EP content at $4.0 \%$ - which was deemed as the optimum EP dosage.

Generally, FC has high permeability coefficients [5, 25]. Throughout the FC specimens containing zero EP, many gaps and pores facilitated water migration due to pressure differences and capillary action when pressure was applied. When EP was added, the average pore size and size distribution decreased as was shown in Figure 11. This was attributed to the fact that the EP served to fill in the gaps in the pore walls formed by the hydrated products, which extended or blocked the water migration pathways and improved the impermeability characteristics of FC. However, this also infers that only a proportion of the pores could be back filled with water [45].
As evident in Figure 14, the permeability coefficient increased dramatically when the EP content reached $4.5 \%$, with a $K_{P}$ value of about $47.50 \times 10^{-9} \mathrm{~mm} / \mathrm{h}$ versus about $0.75 \times 10^{-9} \mathrm{~mm} / \mathrm{h}$ (lowest $K_{P}$ value) for $4.0 \% \mathrm{EP}$. This was attributed to the high viscosity of concrete slurry at high EP levels that created difficulties in mixing, thus leading to poor foam homogeneity, stabilization, bonding, and pore interconnections. All these factors were detrimental to the impermeability characteristics of FC. However, it was also possible that the amount of water absorbed within the FC was dependent on both the wettability and water binding ability of the outer surfaces of the test specimens and the internal pore surfaces. This phenomenon was further explored with the SE (contact angle) measurements that are presented and discussed in the subsequent text.

4.2.2. Effects of SE on the Impermeability and Drying Shrinkage of FC. The contact angle (CA) and SE results for all the test specimens are summarized in Table 8 and also 


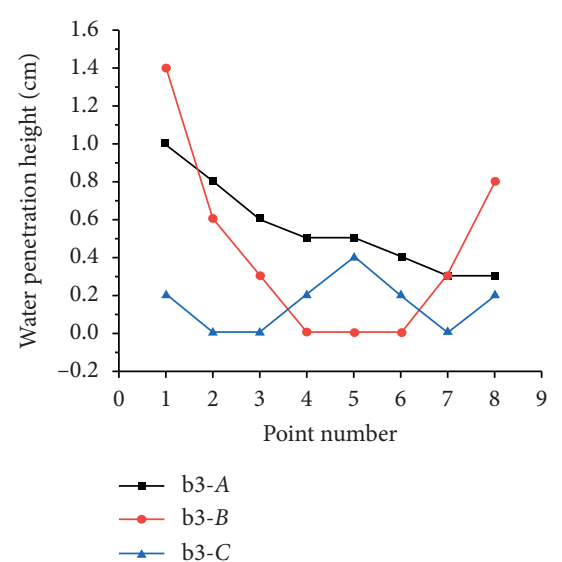

(a)

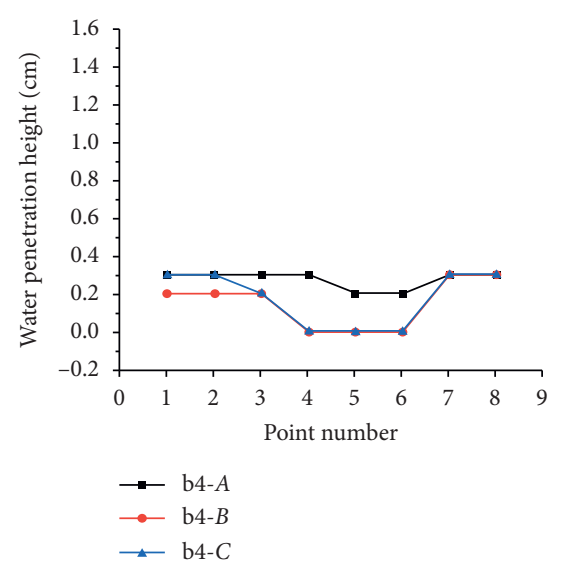

(b)

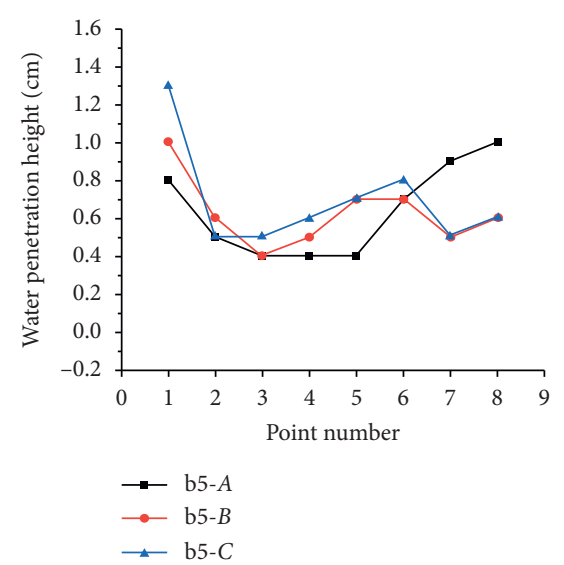

(c)

Figure 13: Measured values of the water exudation height of specimens (a) b3, (b) b4, and (c) b5. Data for three separate specimens $A$ (black), $B$ (red), and $C$ (blue) are displayed in each figure.

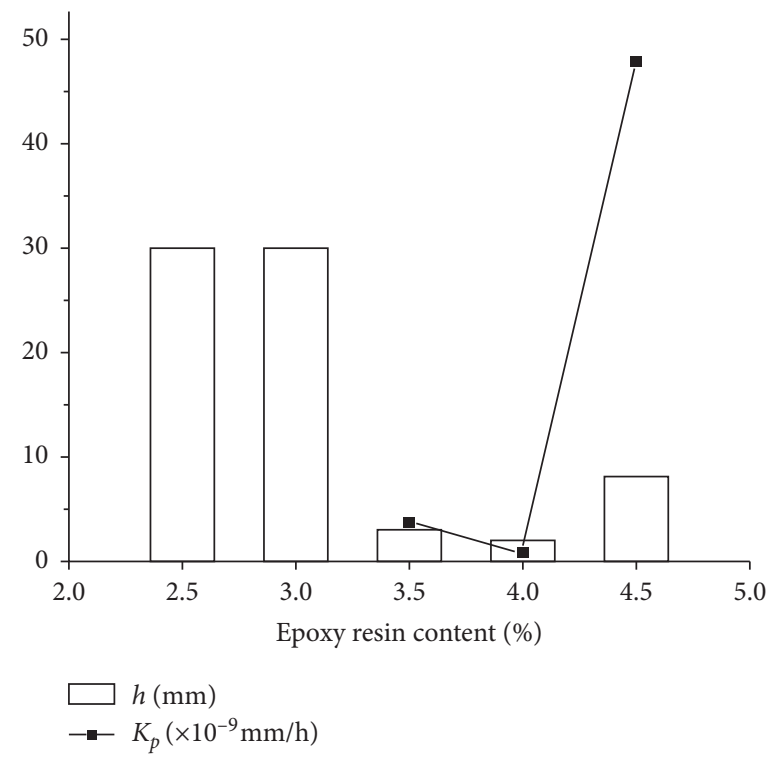

FIgURE 14: Values of penetration depth, $h$, and permeability coefficient, $K_{P}$, of the FC specimens with different contents EP contents.

plotted in Figure 15, respectively. The relationship between the impermeability and drying shrinkage resistance of FC and SE and CA needs comprehensive analysis and cannot be generalized $[17,19,27,41,42]$. Between EP contents of $2.5 \%$ and $4.0 \%$, the contact angles were greater than $90^{\circ}$, indicating lower wettability and better adhesion/bonding [42]. The contact angles for test specimens with EP contents of $0 \%$ and $4.5 \%$ were $88.6^{\circ}$ and $82.7^{\circ}$, respectively, which suggested that the wettability was relatively high with poor adhesion/ bonding characteristics than the other EP contents.

The contact angle measurements only describe the wettability of the outer surface of test specimens, which is not related to the water adsorption ability of the pores. This is the main factor that dictates impermeability in FC. The penetration of water into FC reduced the SE, which in turn reduced the energy required to form a crack, and easily caused the interconnection of pores throughout the concrete matrix [41, 42]. This is detrimental to the impermeability and the resistance to drying shrinkage.

As seen in Figure 15, the SE of specimen b4 was by far the largest, in magnitude, which reflected the previous observations that specimen b4 (with $4.0 \%$ EP) had the lowest permeability coefficient and the highest resistance to drying shrinkage, respectively. If the initial SE was lower, and, therefore, the energy required to form microcracks is low, channels through which water can flow will be formed throughout the concrete under the application of water pressure. However, when the SE is high, the water pressure in the capillary is not enough to trigger the formation of microcracks, and the capillary action of water is also prevented. Overall, the penetration of water throughout the FC matrix is minimized. By 
TABLE 8: Measured values of the CA and SE.

\begin{tabular}{lcccccc}
\hline Specimen groups & b0 & b1 & b2 & b3 & b4 & b5 \\
\hline $\mathrm{CA}\left({ }^{\circ}\right)$ & 88.60 & 100.20 & 115.30 & 90.70 & 107.30 & 87.20 \\
SE $(\mathrm{mN} / \mathrm{m})$ & 61.97 & 77.80 & 84.19 & 101.57 & 140.85 & 71.66 \\
\hline
\end{tabular}

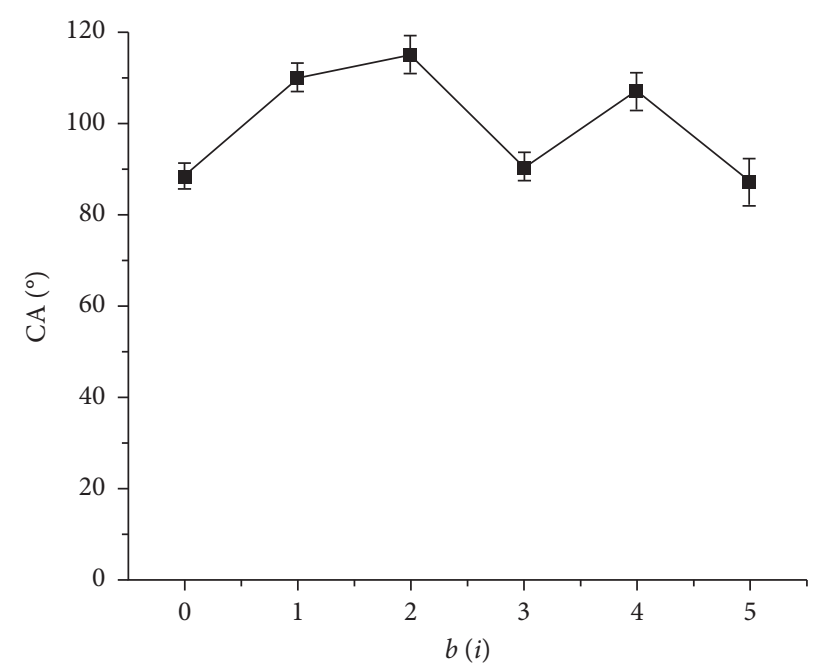

(a)

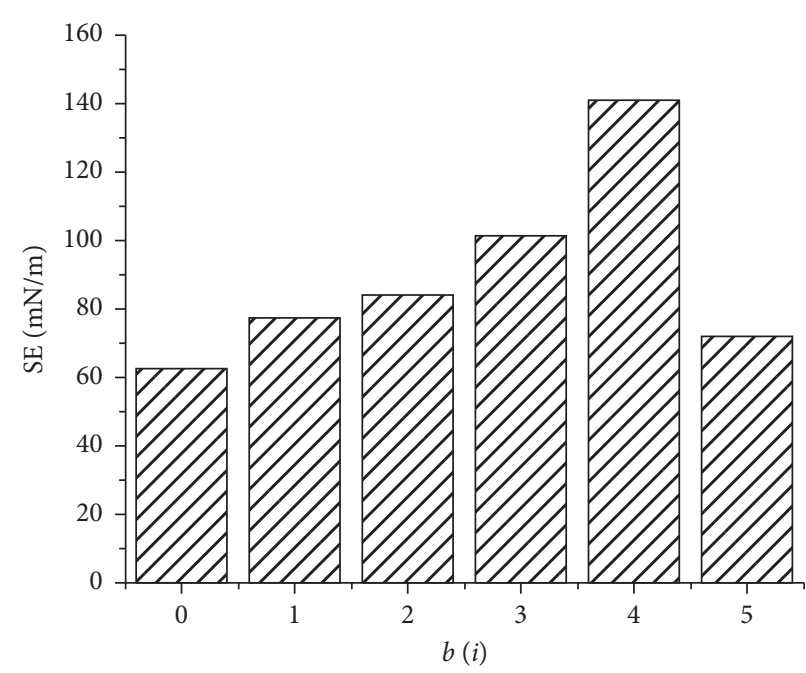

(b)

Figure 15: (a) Measured contact angles and (b) calculated surface energies (b) of FC specimens containing increasingly higher amounts of EP.

introducing EP into FC, the network channels through which water can flow are longer, and many pores become simultaneously blocked, thus enhancing the FC's impermeability characteristics whilst increasing its resistance to drying shrinkage.

\section{Conclusions and Recommendations}

The influence of EP content on the drying shrinkage, impermeability, internal pore structure, and SE of FC with a low water-to-cement ratio was evaluated in this study. Laboratory testing was conducted to characterize the physical and chemical properties of the EP-modified FC including permeability, drying shrinkage, SEM, and SE tests.

The study findings indicated that the amount of drying shrinkage of FC increased with decreasing moisture content and that the shrinkage value becomes less affected by the decrease of moisture content after the addition of EP. An increase in curing time also leads to an increase in the drying shrinkage, where the rate of drying shrinkage followed an exponential decay for up to 56 days.

The addition of EP was shown to enhance both the resistance to drying shrinkage and impermeability. An optimum EP content of $4.0 \%$ was found to display the best performance for both effects compared to the unmodified FC, with the drying shrinkage reduced by $48 \%$ and the impermeability pressure increased in excess of $600 \%$. An excessive dosage of EP above $4.0 \%$ led to poor performance in terms of both the resistance to drying shrinkage and impermeability.
Analysis of the FC microstructure revealed that the EP filled and densified the pores, voids, and pore walls. The membranous EP component also formed a micromesh structure that bonded the hydration products together. An increase in the pore number and a decrease in the average pore size were observed, which suggested that the improved shrinkage resistance was caused by an increase in the length of the internalized channels, through which water must migrate.

Lastly, an analysis of the SE showed that EP increased the contact angle, which reduces wettability. The maximum SE was obtained when the EP content was $4.0 \%$, where the highest SE provided the highest resistance to microcracking, as well as the weakest capillary action for the migration of water within the FC matrix.

Overall, the study has shown that the addition of a polymeric additive, namely, EP, to FC significantly improved the properties and performance of FC in terms of the impermeability characteristics and resistance to drying shrinkage. For the materials and laboratory tests conducted in this study, $4.0 \%$ was found as the optimum EP dosage to maximum the impermeability properties and drying shrinkage resistance of FC. Although limited to the specific materials discussed in the paper, the study findings, no doubt, provide a launch-pad for further in-depth research into polymeric additives (such as EP) to enhance FC including field validation and practical applications. By increasing the properties of FC such as impermeability and shrinkage, it can not only increase the durability of the material itself, but also be better used for building 
compensation foundation filling, highway subgrade backfilling, and roadbed widening.

\section{Data Availability}

The data used to support the findings of this study are available from the corresponding author upon request.

\section{Conflicts of Interest}

The authors declare that they have no conflicts of interest regarding the publication of this paper.

\section{Acknowledgments}

The authors gratefully thank Professor Jiusu Li for his technical advice and suggestions. Special thanks and due gratitude also go to all those who helped during the course of this study.

\section{References}

[1] T. Richard, J. Dobogai, T. Gerhardt, and W. Young, "Cellular concrete-a potential load-bearing insulation for cryogenic applications?" IEEE Transactions on Magnetics, vol. 11, no. 2, pp. 500-503, 1975.

[2] E. K. K. Nambiar and K. Ramamurthy, "Sorption characteristics of foam concrete," Cement and Concrete Research, vol. 37, no. 9, pp. 1341-1347, 2007.

[3] M. Madjoudj, M. Quenendec, and R. M. Dheilly, "Water capillary absorption of cellular clayed concrete obtained by proteinic foaming," in Innovations and Development in Concrete Materials and Construction, R. K. Dhir, P. C. Hewelett, and L. J. Csetenyi, Eds., pp. 513-521, Thomas Telford, London, UK, 2002.

[4] P. Prim and F. H. Wittmann, "Structure and water absorption of aerated concrete," in Autoclaved Aerated Concrete, Moisture and Properties, F. H. Wittmann, Ed., pp. 43-53, Elsevier, Amsterdam, The Netherlands, 1983.

[5] R. Wang, P. Gao, M. Tian, and Y. Dai, "Experimental study on mechanical and waterproof performance of lightweight foamed concrete mixed with crumb rubber," Construction and Building Materials, vol. 209, pp. 655-664, 2019.

[6] S. Mindess, Developments in the Formulation and Reinforcement of Concrete, Wood Head Publishing and Maney Publishing, Institute of Materials, Minerals \& Mining CRC press, Washington, DC, USA, 2014.

[7] Y. W. Wang, Experimental Study on the Durability of Lightweight Concrete and its Lifting Technology, Southwest Jiaotong University, Chengdu, China, 2017.

[8] E. K. K. Nambiar and K. Ramamurthy, "Influence of filler type on the properties of foam concrete," Cement and Concrete Composites, vol. 28, no. 5, pp. 475-480, 2006.

[9] L. K. Aggarwal, P. C. Thapliyal, and S. R. Karade, "Properties of polymer-modified mortars using epoxy and acrylic emulsions," Construction and Building Materials, vol. 21, no. 2, pp. 379-383, 2007.

[10] M. Al-nasra and M. Daoud, "Study of the ability of cracked concrete to sample water flow, concrete mixed with super absorbent polymer," Engineering Applications of Artificial Intelligence, vol. 24, no. 1, pp. 274-281, 2017.

[11] W. She, Y. Du, C. Miao et al., "Application of organic- and nanoparticle-modified foams in foamed concrete: reinforcement and stabilization mechanisms," Cement and Concrete Research, vol. 106, pp. 12-22, 2018.

[12] K. Ramamurthy, E. K. Kunhanandan Nambiar, and G. Indu Siva Ranjani, "A classification of studies on properties of foam concrete," Cement and Concrete Composites, vol. 31, no. 6, pp. 388-396, 2009.

[13] M. B. Youssef, F. Lavergne, K. Sab, K. Miled, and J. Neji, "Upscaling the elastic stiffness of foam concrete as a threephase composite material," Cement and Concrete Research, vol. 110, pp. 13-23, 2018.

[14] M. Cong and C. Bing, "Properties of a foamed concrete with soil as filler," Construction and Building Materials, vol. 76, no. 76, pp. 61-69, 2015.

[15] J. Zhang, Le Ding, F. Li et al., "Recycled aggregates from construction and demolition wastes as alternative filling materials for highway subgrades in China," Journal of Cleaner Production, vol. 255, Article ID 120223, 2020.

[16] X. Tan, W. Chen, H. Liu et al., "A combined supporting system based on foamed concrete and U-shaped steel for underground coal mine roadways undergoing large deformations," Tunnelling and Underground Space Technology, vol. 68, pp. 196-210, 2017.

[17] A. Sychova, M. Sychov, and E. Rusanova, "A method of obtaining geonoiseprotective foam concrete for use on railway transport," Procedia Engineering, vol. 189, pp. 681-687, 2017.

[18] E. K. K. Nambiar and K. Ramamurthy, "Air-void characterisation of foam concrete," Cement and Concrete Research, vol. 37, no. 2, pp. 221-230, 2007.

[19] M. Hori, "The strength of cement based materials from the viewpoint of surface energy," Journal of the Ceramic Association, vol. 70, pp. 54-59, 1962.

[20] D. J. Cook and M. N. Haque, "Strength reduction and length changes in concrete and mortar on water and methanol sorption," Cement and Concrete Research, vol. 4, no. 5, pp. 735-744, 1974.

[21] T. Okajima and T. Ishikawa, "Moisture content dependency of the strength of cement based materials from the viewpoint of surface energy," Annual Reports on the Progress of Chemistry, vol. 35, pp. 130-133, 1981.

[22] S. Okish and H. Ono, "Effect of moisture content on creep of concrete under uniaxial and triaxial compressive stress at normal temperature," Journal of the Society of Materials Science, vol. 34, no. 376, pp. 8-13, 1985.

[23] S. Asamoto and T. Ishide, "Microscopic approach to timedependent deformation mechanism of concrete based on liquid characteristics," Journal of Materials Science, vol. 50, no. 760, pp. 159-172, 2003.

[24] J. Zhang, F. Gu, and Y. Zhang, "Use of building-related construction and demolition wastes in highway embankment: laboratory and field evaluations," Journal of Cleaner Production, vol. 230, pp. 1051-1060, 2019.

[25] C. Ma and B. Chen, "Properties of foamed concrete containing water repellents," Construction and Building Materials, vol. 123, pp. 106-114, 2016.

[26] X. S. Ma, Research on Polymer Composite Foam Concrete Materials, North China University of Science and Technology, Qinhuangdao, China, 2018.

[27] A. A. Griffith, "The phenomenon of rupture and flow in solid," Philosophical Transactions of the Royal Society A, vol. 221, pp. 163-198, 1920.

[28] G. R. Irwin, "Analysis of stresses and strains near the end of a crack traversing," Journal of Applied Mechanics, vol. 24, pp. 361-364, 1957.

[29] D. H. Xu and M. Xu, Introduction to Concrete Materials, China Standard Press, Beijing, China, 2002. 
[30] ASTM C157, Standard Test Method for Length Change of Hardened Hydraulic Cement Mortar and Concrete, American Society for Testing and Materials, West Conshohocken, PA, USA, 2008.

[31] C. X. Zhao, Experimental Study on Polymer Modified CementBased Foam Concrete, Chongqing University, Chongqing, China, 2012.

[32] GB175-2007, Common Portland Cement, Standards Press of China, Beijing, China, 2007.

[33] BS EN, Methods of Testing Cement, The British Standards Institution, London, UK, 2005.

[34] Z. M. Zhou, Research on High-Strength Foam Concrete, Hunan University, Changsha, China, 2011.

[35] BS EN, BS EN 934-2 Admixtures for Concrete, Mortar and Grout-Part 2: Concrete Admixtures-Definitions, Requirements, Conformity, Marking and Labelling BSI, The British Standards Institution, London, UK, 2001.

[36] ASTM C618, Standard Specification for Coal Fly Ash and Raw or Calcined Natural Pozzolan for Use in Concrete, American Society for Testing and Materials, West Conshohocken, PA, USA, 2002.

[37] Z. Y. Huang, Q. F. Sun, and Z. M. Zhou, "Pore structure and properties of silicate-sulfoaluminate cement ultralift foam concrete," Bulletin of the Chinese Ceramic Society, vol. 32, no. 9, pp. 1894-1899, 2013.

[38] GB/T11969, Test Methods of Autoclaved Aerated Concrete, Standards Press of China, Beijing, China, 2008.

[39] GB/T50082, Standard for Test Methods of Long-Term Performance and Durability of Ordinary Concrete, China Architecture \& Building Press, Beijing, China, 2009.

[40] L. Lin, Research on the Properties of Go/carbon Nanotube Cement Matrix Composites, Hunan University, Changsha, China, 2018.

[41] Z. W. Sun, Influence of Surface Energy on Fracture Energy and Strength of Cement-Based Materials, Qingdao University of Technology, Qingdao, China, 2008.

[42] L. F. Walubita, S. I. Lee, A. N. Faruk et al., Texas Flexible Pavements and Overlays: Year 5 Report-Complete Data Documentation (No. FHWA/TX-15/0-6658-3), Texas A\&M Transportation Institute, College Station, TX, USA, 2017.

[43] Y. H. M. Amran, N. Farzadnia, and A. A. Abang Ali, "Properties and applications of foamed concrete; a review," Construction and Building Materials, vol. 101, no. 1, pp. 990-1005, 2015.

[44] E. K. K. Nambiar and K. Ramamurthy, "Shrinkage behavior of foam concrete," Journal of Materials in Civil Engineering, vol. 21, no. 11, pp. 631-636, 2009.

[45] E. P. Kearsley and P. J. Wainwright, "Porosity and permeability of foamed concrete," Cement and Concrete Research, vol. 31, no. 5, pp. 805-812, 2001. 